\title{
Surface Wettability Controllable Polyimides Having Various Functional Groups by UV Light Irradiation
}

\author{
Yusuke Tsuda \\ Department of Biochemistry \& Applied Chemistry \\ Kurume National College of Technology, \\ Komorino 1-1-1, Kurume, Fukuoka 830-8555, Japan \\ tsuda@kurume-nct.ac.jp
}

\begin{abstract}
The soluble polyimides were synthesized from tetracarboxylic dianhydrides such as $3,4^{\prime}$-oxydiphthalic anhydride $\left(3,4^{\prime}\right.$-ODPA) and diamine monomers having various functional groups such as long-chain alkyl groups, natural products, unsaturated longchain alkyl group, t-Boc or $o$-nitrobenzyl group. The thin films of obtained polyimides were irradiated by UV light ( $\lambda \max ; 254 \mathrm{~nm}$ or $365 \mathrm{~nm})$, and the contact angles for the water decreased from near $100^{\circ}$ (hydrophobicity) to minimum $20^{\circ}$ (hydrophilicity) in proportion to irradiated UV light energy. From the result of contact angle measurements and the result of the ATR and XPS analysis, it is recognized that the hydrophobic groups on the polyimide surface decrease and the hydrophilic groups such as carboxyl groups and hydroxyl groups generate on their surface. Thus, the surface wettability of these polyimides can be controlled by UV light irradiation.
\end{abstract}

Keyword: Polyimide, Functional group, UV light irradiation, Surface wettability, Printed electronics

\section{Introduction}

Polyimides exhibit excellent thermal and mechanical properties, and have extensive engineering and microelectronics applications $[1,2]$. Since conventional aromatic polyimides are insoluble, extensive research has been carried out to improve the solubility of polyimides. Our research group has systematically investigated the synthesis and characterization of soluble polyimides based on aromatic diamines bearing long-chain alkyl groups, and the results from this research were described in the review papers $[3,4]$.

Recently, the printed electronics technology, by which the conductive lines (circuit) can be printed onto the plastic substrate, has been investigated. Polyimide films are the most promising plastics for use in printed electronics because of their high thermal stability. Various approaches such as the use of repellent pore-structured polyimide films [5], the surface energy controlled ink-jet printing with UV irradiation [6], have been investigated to obtain the fine patterning. Recently, the authors also have investigated the surface wettability control of polyimides having hydrophobic groups such as long-chain alkyl groups by UV light irradiation [7-17]. The basic concept of these surface wettability controllable polyimides is shown in Fig. 1. In this paper, the author review our previous research on the surface wettability controllable polyimides having various functional groups such as long-chain alkyl groups (Group-1), natural products (Group-2), unsaturated longchain alkyl group (Group-3), t-Boc or $o$ nitrobenzyl group (Group-4) investigated in our laboratory (Fig. 2).

\section{Experimental}

2.1. Materials

5-(2,5-Dioxotetrahydrofuryl)-3-methyl-3cyclohexene-1,2-dicarboxylic anhydride (Cyclohexene-DA, EPICLON B-4400) was 


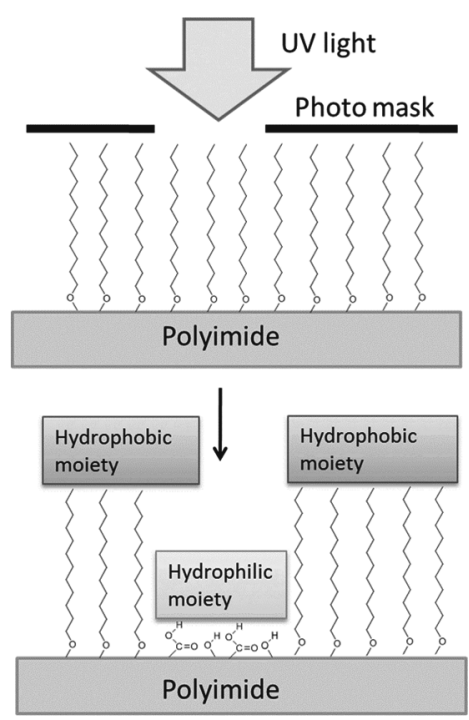

Fig. 1. Conceptual scheme of wettability control of the polyimide surface by UV irradiation.

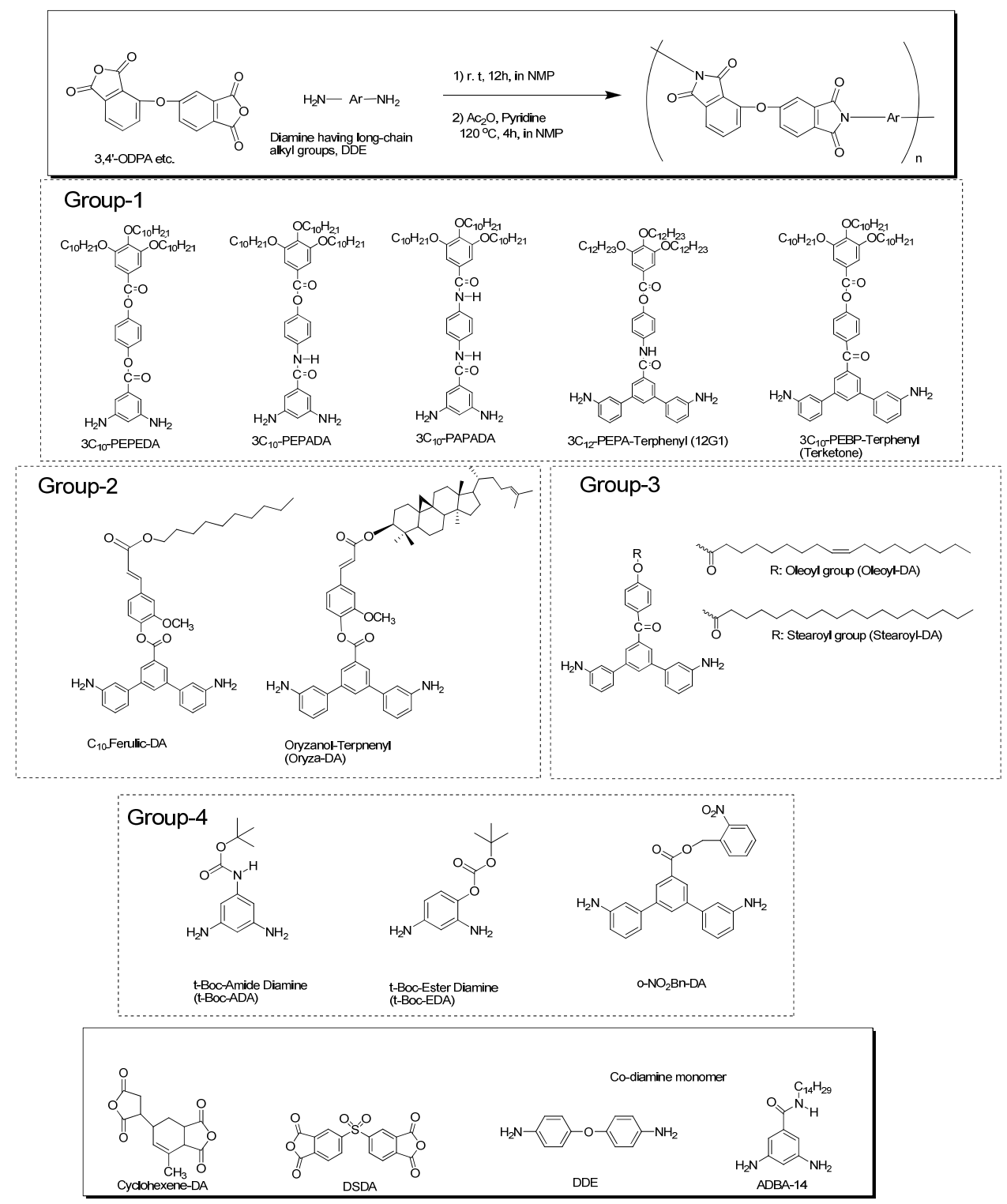

Fig. 2. Surface wettability controllable polyimides containing functional diamine monomers. 
purchased from DIC Corporation and recrystallized from acetic anhydride (mp. $175.1^{\circ} \mathrm{C}$ ). $\quad 3,3^{\prime}, 4,4^{\prime}$-Diphenylsulfonetetra carboxylic dianhydride (DSDA) was purchased from New Japan Chemical Co., Ltd. and recrystallized from acetic anhydride (mp. $291.0{ }^{\circ} \mathrm{C}$ ). 4,4'-Diaminodiphenylether (DDE) from Seika Corporation and 3,4'oxydiphthalic anhydride (3,4'-ODPA; asymmetric-ODPA; a-ODPA) from Shanghai Research Institute of Synthetic Resins were used after drying in a vacuum oven. Ultra-pure grade of N-methyl-2-pyrrolidone (NMP) was purchased from Kanto Chemical Co., Inc. and used as received. Other reagents were purchased from TCI or Wako Pure Chemical Industries (Wako) and used as received.

\subsection{Synthesis of surface wettability controllable polyimides}

Polyimides consist of two monomer units, tetracarboxilic anhydride and aromatic diamine. Generally, the synthesis of functional diamine is more convenient than the synthesis of functional tetracarboxilic anhydride. Therefore, we have performed a variety kind of organic synthesis to obtain the functional diamine monomers for this study. Two main synthetic methods are the reduction of dinitrobenzene precursors, and Suzuki coupling reaction using aminophenyl boranic acid and dibromobenzene precursors. The experimental detail of the synthesis of these functional diamine monomers and the corresponding polyimides have been described in previous papers [3,4,7-17]. Figure 2 shows the library of these polyimides and functional diamine monomers.

\subsection{Measurements}

${ }^{1} \mathrm{H}$ NMR spectra were measured on a JEOL JNM-AL400 FT NMR in $\mathrm{CDCl}_{3}$ or dimethyl sulfoxide- $\mathrm{d}_{6}$ with tetramethylsilane (TMS) as an internal reference. Size exclusion chromatography (SEC) measurements were performed in NMP containing $10 \mathrm{mM} \mathrm{LiBr}$ at $40{ }^{\circ} \mathrm{C}$ with a TOSOH HLC-8020 equipped with a TSK-GEL ALPHA-M using a series of polystyrenes as a standard. Thermogravimetric analysis (TGA) was performed on a Shimadzu TGA-50 in air or under nitrogen (50 $\mathrm{mL} / \mathrm{min})$, and $10 \%$ weight loss temperatures $\left(T \mathrm{~d}_{10}\right)$ were calculated from the second heating scan after cooling from $250{ }^{\circ} \mathrm{C}$. Differential scanning calorimeter (DSC) traces were measured on a Shimadzu DSC-60 under nitrogen and glass transition temperatures $(T \mathrm{~g})$ were read at the midpoint of the heat capacity jump from the second heating scan.

Polyimide thin films were obtained as follows: $0.5-2.0 \mathrm{wt} \%$ polyimide solution in NMP were dropcasted on glass substrates and the solution were slowly evaporated by heating at approximately 100 $120{ }^{\circ} \mathrm{C}$ until the films were dried, then the films were dried in a vacuum oven at $100{ }^{\circ} \mathrm{C}$ for $12 \mathrm{~h}$. Film preparation by the spin coat method was carried out for the SFM measurement. Water contact angles were measured by SImage mini (Excimer. Inc., Japan) and UV light irradiation were performed using $254 \mathrm{~nm}$ UV lamp unit (E50-254$270 \mathrm{U}-1,254 \mathrm{~nm}, 6.0 \mathrm{~mW} / \mathrm{cm}^{2}$, Excimer. Inc., Japan) or $365 \mathrm{~nm}$ lamp unit (HLR 100T-2, $365 \mathrm{~nm}, 170$ $\mathrm{mW} / \mathrm{cm}^{2}$, SEN Light Corp., Japan) and a cool plate (NCP-2215, NISSIN Laboratory equipment, Japan) adjusted at $20{ }^{\circ} \mathrm{C}$ that was used to neglect the effect of thermal degradation of polyimide films during UV irradiation process.

\section{Results and discussion}

3.1. General properties of polyimides

The molecular weights of obtained polyimides were measured by SEC

$(\mathrm{Mn} ; 3500 \sim 50000$, in $\mathrm{NMP} / 10 \mathrm{mM} \mathrm{LiBr}$ calibrated with polystyrenes), and all polyimides showed the good film forming ability. The thermal properties of these polyimides were estimated by glass transition temperatures $\left(\mathrm{Tg} ; 200 \sim 250{ }^{\circ} \mathrm{C}\right)$ and thermal degradation temperatures $\left(T \mathrm{~d}_{10} ; 400{ }^{\circ} \mathrm{C}\right)$, and these polyimides showed the good thermal stability for heat resistance polymers. In case that 3,4'-ODPA was selected as a tetracarboxilic dianhydride, the high molecular weights and the good solubility were observed. Therefore, 3,4'-ODPA is generally used as a standard tetracarboxilic dianhydride.

3.2. Surface wettability controllable polyimides based on long-chain alkyl groups

The thin films based on the polyimides having long-chain alkyl groups (Group-1, in Fig. 2) were irradiated by UV light ( $254 \mathrm{~nm}, 0,2,4,8 \mathrm{~J})$, then the contact angles for the water were measured. Figure 3 shows UV irradiation energy dependence of water contact angles of polyimide films based on 3,4'- 
ODPA/DDE, 3,4'-ODPA/3C 10 -PEPADA, 3,4'ODPA/3C 10 -PAPADA, $^{3} 4^{\prime}$-ODPA $/ 3 \mathrm{C}_{10^{-}}$ PEBPDA, respectively. The high water contact angles of polyimides bearing long-chain alkyl groups decreased from near $100^{\circ}$ (hydrophobicity) to the minimum value, $20^{\circ}$ (hydrophilicity) in proportion to irradiated UV light energy. It is considered that these changes of wettability of polyimides are mainly based on the photo-oxidation, photo-degradation, and scission of long-chain alkyl groups and specific functional groups such as a ester group, and that the generation of the hydrophilic functional groups such as $\mathrm{COOH}$ and $\mathrm{OH}$ groups probably occurred. Although the water contact angles decreased after UV light irradiation, the degrees of changes depended on the structure of diamine components. In these cases, the water contact angles based on 3,4'-ODPA/3 $\mathrm{C}_{10}$-PEPEDA, $3 \mathrm{C}_{10}$-PEPADA polyimide containing long-chain alkyl groups via phenylester (PE) linkages the most greatly decreased from near $100^{\circ}$ to near $20^{\circ}$. It is speculated that phenylester linkage possibly cause photo reaction such as photo-Fries reaction and generate hydroxyl groups.

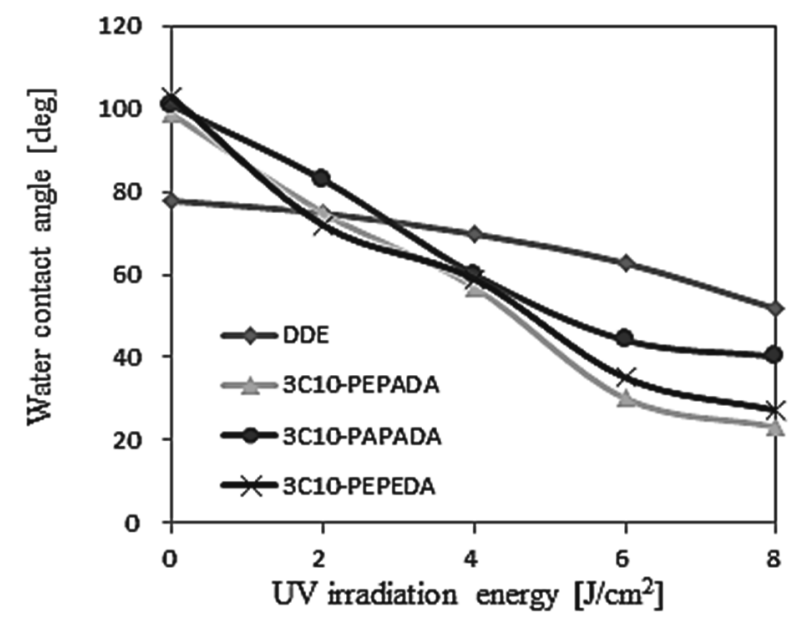

Fig. 3. UV irradiation energy dependence of water contact angles of polyimide films based on 3,4'-ODPA and diamines having long-chain alkyl groups.

As the water contact angles based on 3,4'ODPA/DDE without long-chain alkyl groups also gradually decreased by UV light irradiation, it is imagined that the polyimide back-bones partly oxidized by UV irradiation process. Consequently, it is speculated that the complicated photo-induced reactions such as auto-oxidation, cleavage of ester groups, Fries rearrangement, etc. occur on the surface of polyimides on the course of UV light irradiation process (Fig. 4).

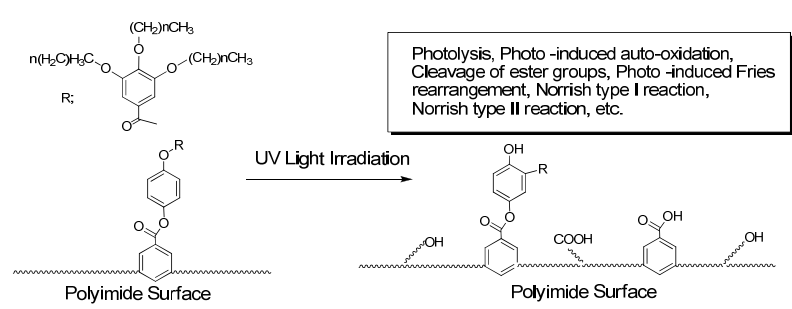

Fig. 4. Anticipated photochemical reactions on the surface of polyimides containing long-chain alkyl groups $(\lambda \max ; 254 \mathrm{~nm})$.

3.3. Surface wettability controllable polyimides based on natural products

The novel diamine monomers (Group-2, in Fig. 2) for surface wttability controllable polyimides were successfully synthesized from natural products such as ferulic acid and $\gamma$-oryzanol. The drastic simplification of the synthetic route was accomplished by using natural chemical compounds. The thin films of obtained polyimides were irradiated by UV light $(\lambda \max ; 254 \mathrm{~nm})$, and the contact angles for the water decreased from $90-100^{\circ}$ (hydrophobicity) to minimum $35^{\circ}$ (hydrophilicity) in proportion to irradiated UV light energy (Fig. 5). Polyimides based on 3,4'ODPA/Oryza-DA/DDE (100/10/90 mol\%) showed the most drastic wettability change. It can be speculated that a photo reactive Cinnamic acid skeleton and a cholesterol unit included in OryzaDA effectively contribute.

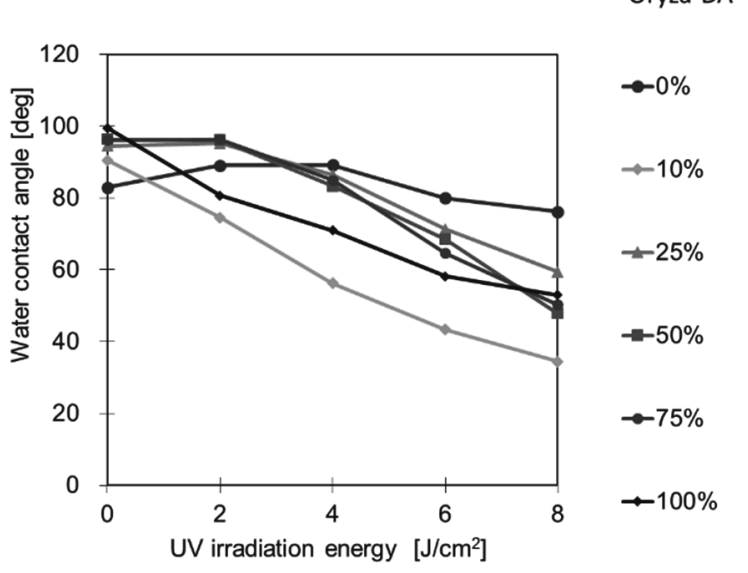

Fig. 5. UV irradiation energy dependence of water contact angles of polyimide films based on 3,4'-ODPA/ Oryza-DA /DDE ( $\lambda \max ; 254 \mathrm{~nm})$. 
3.4. Surface wettability controllable polyimides based on unsaturated long-chain alkyl group

The novel diamine monomers (Group-3, in Fig. 2) for surface wettability controllable polyimides having unsaturated long-chain alkyl group and the corresponding polyimides were successfully synthesized. The thin films of obtained polyimides were irradiated by UV light $(\lambda \max ; 254 \mathrm{~nm})$, and the contact angles for the water decreased from 90-100 (hydrophobicity) to minimum $30^{\circ}$ (hydrophilicity) in proportion to irradiated UV light energy. These changes are larger in the case of polyimides having unsaturated longchain alkyl group than in the case of polyimides having saturated long-chain alkyl group. The introduction of unsaturated longchain alkyl group is the effective method for the improvement of surface wettability control of polyimides by UV light irradiation. It is considered that these changes of wettability of polyimides are mainly based on the photodegradation of double bond in Oleoyl-DA unit and the scission of specific functional groups such as an ester group, and that the generation of the hydrophilic functional groups such as $\mathrm{COOH}$ and $\mathrm{OH}$ groups probably occurred.

3.5. Surface wettability controllable polyimides based on photo reactive groups

In the previous sections (3.2-3.4), the surface wettability control has been carried out by UV light irradiation ( $\lambda \max ; 254 \mathrm{~nm}$ ). However, $254 \mathrm{~nm}$ UV light is powerful, and many organic compounds are easily decomposed by photo-oxidation. In fact, the wettability changes of the polyimides developed in our laboratory seems to be caused mainly by the photo-oxidation reactions. In addition, the energy efficiency of $254 \mathrm{~nm}$ UV light irradiation is worse than the one of $365 \mathrm{~nm}$ UV light irradiation that is preferable wavelength in industry. Consequently, the author has focused on tert-butoxycarbonyl (t$\mathrm{Boc})$ group and $o$-nitrobenzyl $\left(o-\mathrm{NO}_{2} \mathrm{Bn}\right)$ group that is the protecting group of amino group and/or hydroxyl group and easily deprotected by UV light irradiation $(365 \mathrm{~nm})$.

The thin films based on the polyimides having photo reactive group (Group-4, in Fig. 2) were irradiated by UV light ( $365 \mathrm{~nm}, 0,5,10,15,20 \mathrm{~J})$, then the contact angles for the water were measured. Does of $5 \mathrm{~J}$ correspond $1 \mathrm{~min}$ UV irradiation. Figure 6 shows UV light irradiation energy dependence for water contact angles of polyimide films based on 3,4'-ODPA/t-Boc ADA/ADBA-14 polyimides and copolyimides, and 3,4'-ODPA/t-Boc EDA/ADBA14 polyimides and copolyimides respectively. 3,5Diamino- $N$-tetradecylbenzamide (ADBA-14) [18], diamine co-monomer was introduced to enhance the initial hydrophobicity. The water contact angles of initial polyimide films before UV irradiation were around $100^{\circ}$. These high hydrophobicity are probably due to the hydrophobic property of t-Boc group and long-chain alkyl group. These high water contact angles of polyimides having hydrophobic groups decreased in proportion to irradiated UV light energy. The changes of wettability by UV light irradiation are larger in the case of polyimides containing t-Boc EDA group than in the case of polyimides containing t-Boc ADA group. Especially, the contact angles of 3,4'ODPA/t-Boc EDA (100/100) drastically decreased from near $105^{\circ}$ (hydrophobicity) to the minimum value, $60^{\circ}$ (hydrophilicity).
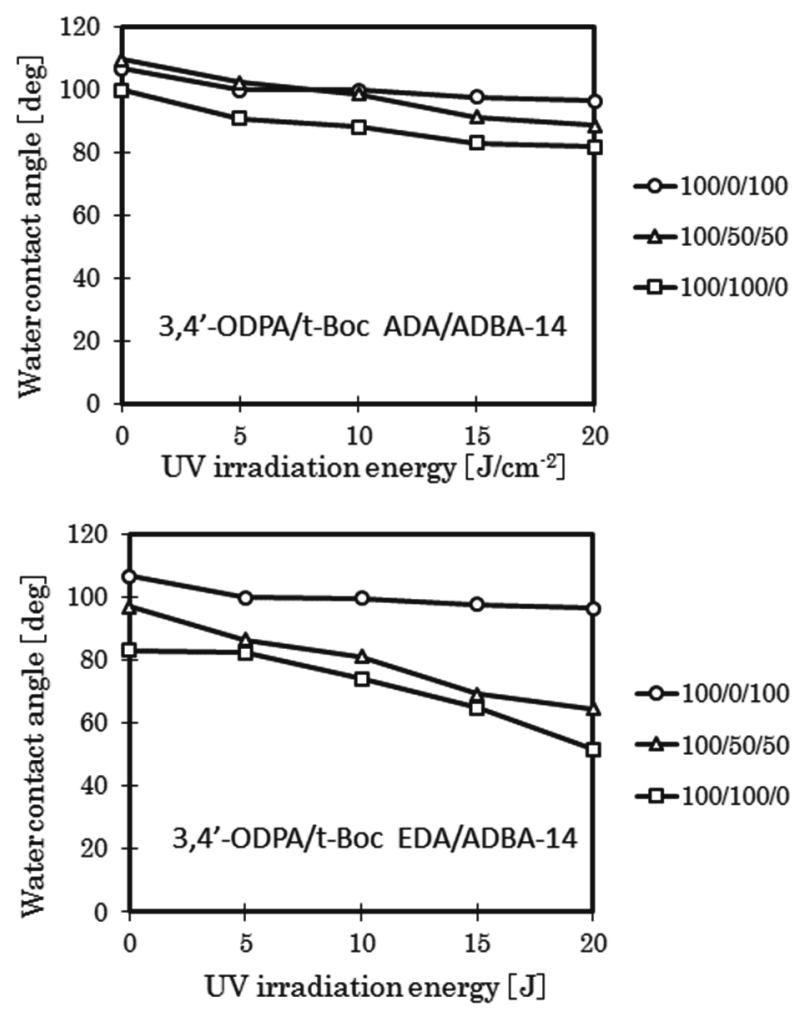

Fig. 6. UV irradiation energy dependence of water contact angles of polyimide films based on; 3,4'ODPA/t-Boc-ADA/ADBA-14 (upper), 3,4'-ODPA/tBoc -EDA/ADBA-14 (under) ( $\lambda \max ; 365 \mathrm{~nm})$.

On the other hand, the water contact angles of polyimde films based on 3,4'-ODPA/ADBA-14 slightly decreased by UV light irradiation. 
Consequently, the introduction of t-Boc group in the polyimide back-bones is effective for the changes of surface wettability from hydrophobicity to hydrophilicity. The introduction of t-Boc EDA is more effective than the introduction of $\mathrm{t}$-Boc ADA. It is speculated that the cleavage of t-Boc group may not occur due to the stability of carbamate linkages in t-Boc ADA group in comparison with carbonate linkages in $\mathrm{t}$-Boc EDA group. It can be also speculated that the generation of hydroxyl groups is occurred by the specific photoreaction such as t-Boc cleavage catalyzed by acidic species on the polymer surface that generate on the course of UV light irradiation process (Fig. 7).

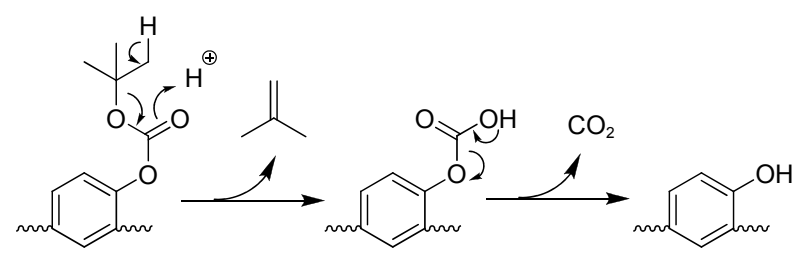

t-Boc cleavage catalyzed by acidic species on the polymer surface

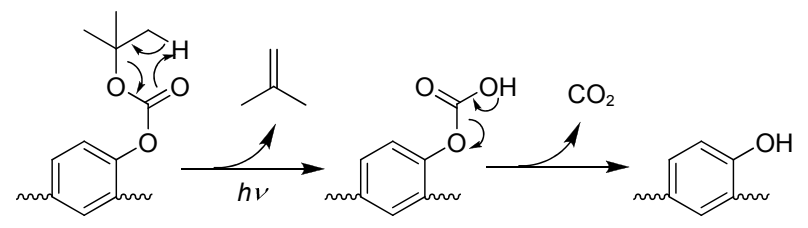

[3,3]-Sigamatropic rearrangement

Fig. 7. Elucidated reaction mechanism on the polyimide surface containing t-Boc-EDA group by UV light irradiation $(\lambda \max ; 365 \mathrm{~nm})$.

Figure 8 shows UV light irradiation energy dependence of water contact angles of polyimide films based on 3,4'-ODPA $/ o-\mathrm{NO}_{2} \mathrm{Bn}-\mathrm{DA}, 3,4^{\prime}$ ODPA/ ADBA-14, 3,4'-ODPA/DDE respectively. The initial water contact angles of polyimide films based on 3,4'-ODPA $/ o-\mathrm{NO}_{2} \mathrm{Bn}-\mathrm{DA}$ and 3,4'ODPA/DDE before UV light irradiation show the similar value, around $90^{\circ}$. The water contact angles of the polyimide based on 3,4'-ODPA $/ o-\mathrm{NO}_{2} \mathrm{Bn}$ DA decreased from $88.1^{\circ}$ to $58.8^{\circ}$ by UV light irradiation (Fig. 8), while the water contact angle of the polyimide based on 3,4'-ODPA/DDE showed the similar value even after UV light irradiation. It is speculated that the typical photoreaction of $o-\mathrm{NO}_{2} \mathrm{Bn}$ group occurs $[19,20]$ and hydrophilic groups such as hydroxyl groups and carboxyl groups generate on their surface (Fig. 9).

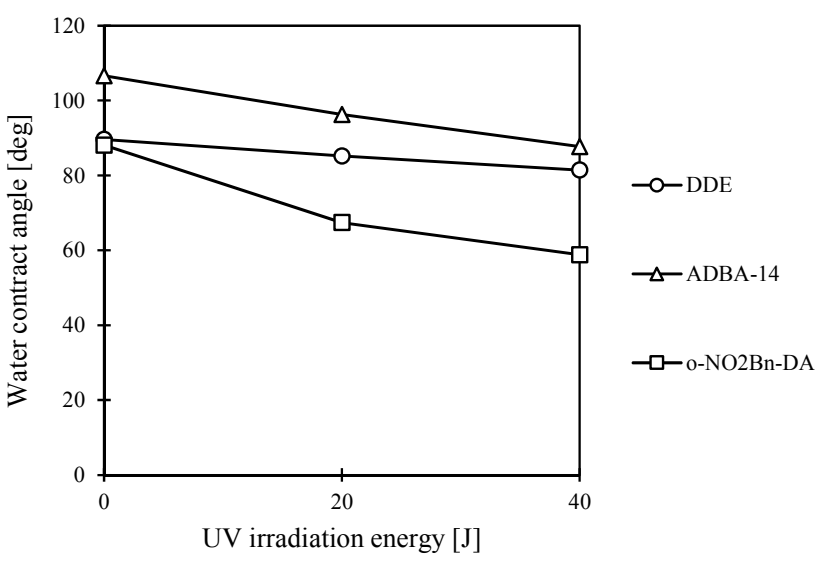

Fig. 8. UV irradiation energy dependence of water contact angles of polyimide films based on 3,4'ODPA $/ o-\mathrm{NO}_{2} \mathrm{Bn}-\mathrm{DA}, \quad 3,4^{\prime}$-ODPA/ADBA-14, 3,4'ODPA/DDE.
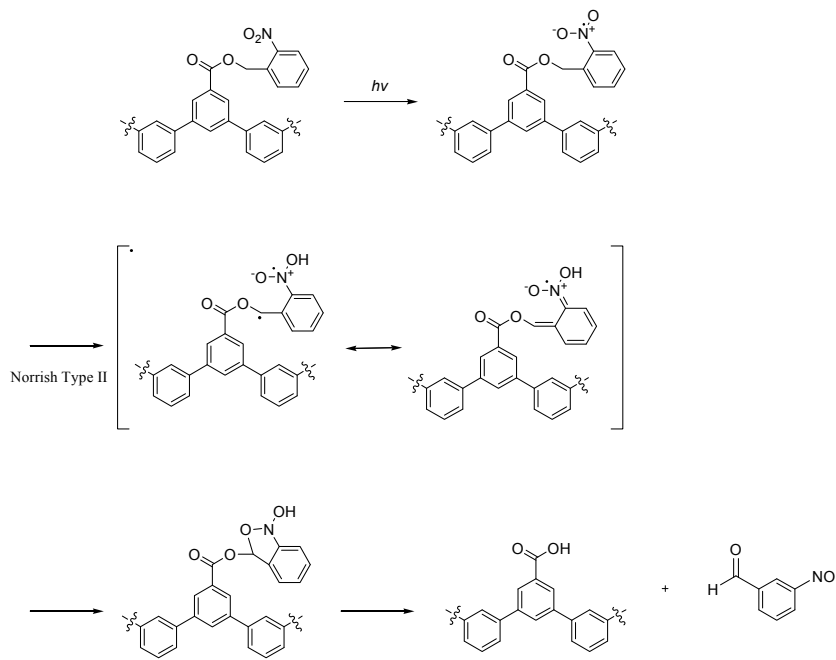

Fig. 9. Elucidated reaction mechanism of $o-\mathrm{NO}_{2} \mathrm{Bn}$ group by UV light irradiation.

By the addition of photo acid generator (PAG), the changes of surface wettability of the polyimide having photo reactive groups were considerably accelerated. However, it is noteworthy that these changes of surface wettability occurs even without PAG, and these results are practically useful in industry. Because, the addition of PAG sometime causes the film properties of polyimide adverse effect, and the residual PAG in a film sometimes causes various physical property adverse effect.

\subsection{Surface analysis experiments}

The surface analysis of the polyimide films were performed by ATR, XPS, SFM (AFM). ATR 
measurements of the polyimide surfaces after UV light irradiation support the assumption that the generation of the hydrophilic functional groups such as $\mathrm{COOH}$ and $\mathrm{OH}$ groups occurred. The absorption of $\mathrm{OH}$ groups around $3300 \mathrm{~cm}^{-1}$ increase, the absorption of alkyl groups around $2900 \mathrm{~cm}^{-1}$ decrease. The intensive surface analysis was examined using XPS and SFM. The generation of hydrophilic moieties was analyzed in detail by XPS narrow scan, and chemical shifts due to $\mathrm{C}-\mathrm{O}$ and $\mathrm{C}=\mathrm{O}$ bonds clearly increase after $\mathrm{UV}$ light irradiation. The surface $\mathrm{nm}$ size micro roughness probably based on long-chain alky groups was observed by SFM analysis. However, the changes of these micro roughness after UV light irradiation were not recognized. Thus, the change of surface wettability of polyimides is mainly occurred by the changes of chemical structures of polyimide surface. These experimental details were reported in our previous papers [7-17].

\section{Conclusion}

The thin films of polyimides having various functional groups were irradiated by UV light, and the contact angles for the water decreased from near $100^{\circ}$ (hydrophobicity) to minimum value, $20^{\circ}$ (hydrophilicity) in proportion to irradiated UV light energy. From the result of surface analyses and various analytical experiments, it is recognized that the hydrophobic groups such as long-chain alkyl groups on the polyimide surface decrease and the hydrophilic groups generate on their surface. The utilization of photo-resist technics using photo reactive groups such as tBoc group and $o$-nitorobenzyl group was successfully investigated. The use of natural product such as $\gamma$-oryzanol drastic simplified the synthetic route of the corresponding dimine monomer. Thus, the surface wettability of the functional polyimides developed in our laboratory can be controlled by UV light irradiation, and these methods are expected to be applied in the field of printed electronics.

\section{Acknowledgement}

This work was supported by JSPS KAKENHI Grant Number 16K05924. This work was performed under the Cooperative Research Program of "Network Joint Research Center for Materials and Devices" (Dr. Atsushi Takahara of Kyushu University). Financial supports from RICOH Co., Ltd. is gratefully acknowledged. The authors thank Shanghai Research Institute of Synthetic Resins for providing 3,4 '-ODPA.

\section{References}

1. "Polyimides", M. Ghosh and K. L. Miital, Eds., Dekker, New York (1996).

2. "Polyimides and Other High Temperature Polymers: Synthesis, Characterization and Applications", M. Ghosh, Ed., Vol. 5, Koninklike Brill NV, Leiden (2009).

3. Y. Tsuda, "Polyimides and Other High Temperature Polymers: Synthesis, Characterization and Applications", M. Ghosh, Ed., Vol. 5, Koninklike Brill NV, Leiden (2009) 17.

4. Y. Tsuda, "Features of Liquid Crystal Display Materials and Processes", N. V. Kamania Ed., Intech, Croatia (2011) 3.

5. C. Kim, M. Nogi, K. Suganuma, and Y. Yamamoto, ACS Appl. Mater. Interfaces, 4 (2012) 2168.

6. K. Suzuki, K. Yutani, M. Nakashima, A. Onodera, S. Mizukami, M. Kato, T. Tano, H. Tomono, M. Yanagisawa, and K. Kameyama, J. Imaging Soc. Jpn., 50 (2011) 142.

7. Y. Tsuda, Y. Hashimoto, and T. Matsuda, Kobunshi Ronbunshu (Japanese), 68 (2011) 24.

8. Y. Tsuda, J. Photopolym. Sci. Technol., 26 (2013) 345.

9. Y. Tsuda and Y. Kawashima, J. Photopolym. Sci. Technol. 27 (2014) 161.

10. Y. Tsuda and S. Kawabata, J. Photopolym. Sci. Technol., 27 (2014) 277.

11. Y. Tsuda, R. Nakamura, S. Osajima, and T. Matsuda, High Perform. Polym., 27 (2015) 46.

12. Y. Tsuda and R. Shiki, J. Photopolym. Sci. Technol., 28 (2015) 191.

13. Y. Tsuda, M. Tahira, N. Shinohara, and D. Sakata, J. Photopolym. Sci. Technol., 28 (2015) 191.

14. Y. Tsuda and D. Sakata, J. Photopolym. Sci. Technol., 29 (2016) 283.

15. Y. Tsuda and R. Shiki, J. Photopolym. Sci. Technol., 29 (2016) 265.

16. Y. Tsuda, J. Photopolym. Sci. Technol., 29 (2016) 383.

17. Y. Tsuda, Kobunshi Ronbunshu (Japanese), 74 (2017) 10.

18. Y. Tsuda, M. Kojima, T. Matsuda, and J.-M. Oh, Polym. J., 40 (2008), 354.

19. M. Edler, S. Mayrbrugger, A. Fian, G. 
Trimmel, S. Rad1, W. Kern, and T. Griesser, J. Mater. Chem. C, 1 (2013) 3931.
20. A. Brown, O. Azzaroni, and W. Huck, Langmuir, 25 (2009) 1744. 